\title{
A visitor's view of Madison's Program for Assertive Community Treatment (PACT)
}

\author{
M. MuiJen, Research Worker, Institute of Psychiatry, De Crespigny Park, London \\ SE5; and G. MCNAMEE, Clinical Nurse Manager, The Maudsley Hospital, Denmark \\ Hill, London SE5
}

Before commencing work on the Daily Living Programme at the Maudsley Hospital, in London, to compare the benefits of community care with standard hospital admission for patients with serious mental illness, a visit to Madison was arranged, where some ten years ago a similar study had been carried out (Stein \& Test, 1980). We had the impression from the substantial literature which has appeared on the mental health service in Madison (Stein \& Test, 1985) that they have implemented in practice their positive research findings on community care. It was felt that their lengthy experience with such a service could be beneficial to the UK, where such services are now being developed. This visit included PACT (Program for Assertive Community Treatment); a research programme investigating the long-term prognosis of mainly schizophrenic patients, and the various units of the mental health services in Madison.

Madison, the state capital of Wisconsin, has a population of some 175,000 persons, which is increased during term periods by some 50,000 students attending its much acclaimed university. Madison is situated in Dane County, one of 72 counties making up the state of Wisconsin. The mental health services have a county catchment area. Laws and guidelines pertaining to mental health are directed from the Wisconsin State Department of Health and Social Services. Public funds for mental health are provided by the state to the county.

PACT is a state supported research project which has been taking responsibility for the long-term care of its patients since 1979. Entry criteria to the PACT programme are: age 18-30, a diagnosis of schizophrenia, schizo-affective disorder, or schizotypal personality disorder, and less than 12 months of accumulated time in psychiatric and penal institutions. Patients are then randomly assigned either to the research programme or to the standard mental health services in Madison. These services are themselves quite community based, and this might well be a confounding factor in the eventual analysis. Evaluation is regularly undertaken by a research team, looking at clinical, social, and economic factors. PACT is a multi-disciplinary team with a staffpatient ratio of $1: 10$. The PACT centre is staffed seven days a week and a telephone on-call system is in operation at night, with home visits being made at night, if necessary.

The approach is rehabilitation, with an emphasis on work and skills teaching. This seems influenced by the vocational counsellors. whose ethos is that work and regular, structured daily activities are as therapeutically important (if not more so) as symptom control and medication. About $40 \%$ of all clients are employed in the competitive job market. In all, $90 \%$ are regularly employed in some way. Most jobs have been obtained with the help of staff; indeed an apparently successful job creation approach is to take employers' numbers from the Yellow Pages and cite the names of other satisfied employers in a bid to find a job which the staff and client deem suitable.

If necessary patients are taken to and from work by staff members, although the experience of the team workers is that prolonged and repeated supervision in the work place is not beneficial to the client and is excessive in the demands it makes on therapist time. Practically all clients are on medication, which is closely monitored, either by clients coming in frequently to collect their medication or by staff carrying out regular home delivery of medication, 'Med-Drops'.

Staff ability to problem solve difficult cases is enhanced by the fact that American courts can order clients to receive treatment in the community. The staff can take over control of a client's money if the client is deemed unable to budget his living expenses. This ability to control the client's purse-strings also benefits cases of secondary alcohol and drug abuse. Living expenses and spending money may be dispensed daily, every few days, weekly or at longer periods if need be.

PACT does not operate on the primary worker system, where the planning and implementation of a client's care is the responsibility of a single staff member. Rather, a case manager coordinates the care of the client, which is shared by some or all of the team members. This allows a greater number of staff to be involved with clients, who appear to be able to interact with all staff members in a therapeutic way.

All clients are visited at their homes regularly, with a frequency varying from once every few weeks for 
someone stable and working to several times daily for someone in crisis. Some clients attend the centre to pick up medication and/or money, others to work in part-time clerical or cleaning jobs, although clients are not encouraged to use the centre as a base or social centre. The vast majority of staff-client, and indeed client-client, interactions occur outside the PACT office.

Crises when they occur, which appeared to be only rarely, possibly because of committed and assertive follow-up, are dealt with in a problem-solving manner. If necessary clients are admitted to hospital for a short period, but this appears to be the exception rather than the rule. Increased visits and changes in medication are often sufficient to defuse the situation.

Several client groups were observed in action, usually with a staff member as facilitator. A woman's group served the dual function of a social group and as a forum to discuss women's issues. Also useful was a symptoms group where clients discussed their symptoms with other clients, and became able to recognise their symptoms, and that they were controllable not only by medication, but by being aware of precipitating stressors and cues such as alcohol and drug abuse. An interesting facet to this group was the total ban on caffeine which is recognised to be one of the most widely abused substances by clients (and staff!).

Morale and motivation among the PACT staff appeared high, and staff turnover low (although nurses seemed an exception, having an intermittently high turnover, the reason for this being unclear). Staff of all disciplines were highly committed, most working over 50 hours weekly.

Pride was taken in the achievements by clients and staff, and clients regularly reported satisfaction with PACT (some expressing surprise and dismay that a similar service was not already operating in a city as renowned as London!).

An important question is the degree to which PACT is helped by being a research programme, without the pressures a statutory service might experience such as sudden emergency admissions, and too many clients. PACT can regulate their intake, yet appear to offer a comprehensive service of a high standard. PACT's clients had impressively good functioning, both vocationally and socially, and it will be interesting to see the comparison with the control group.

There are important similarities between the PACT programme and the statutory service (the mental health centre; MHC) serving Dane County. This is not surprising as the MHC was set up in its present form as a consequence of the original community study of Test \& Stein, of which PACT is a continuation. The adult service of the MHC of Dane County is subdivided into four distinct units, each with its own manager. These units are the Crisis Intervention Service (CIS), the Mobile Community Treatment (MCT), the out-patient Adult Clinical Services (ACS), and Support Network, a day centre. The CIS, MCT, and the ACS are sited in the same building, while Support Network has its own site.

CIS has ten staff members, mainly social workers, with some nursing input. Medical cover is present, although there is no full-time psychiatrist. Crisis intervention is available seven days a week, with night telephone cover and emergency call-out available. Clients can refer themselves by phone, or in person, or may be referred by other agencies. About 160 new referrals are made each month, of which $\mathbf{3 0}$ may be in crisis. Most crisis and other referrals are managed at the MHC itself. Management in the community seems to be the exception. Any discipline may be involved in assessment as indicated. Collaboration with other agencies, including the police, is a strong point, and CIS staff are actively involved in police training programmes. Clients are followed up for relatively long periods, often months, at CIS before being referred to other agencies, such as MCT or Support Network, which accept only fairly stable clients. Over 30 clients attend CIS for medication only.

CIS also supports and counsels the relatives of suicide victims. CIS is contacted by the coroner's office and may contact the relatives by phone or letter depending on the circumstances. This facility is also wellknown to other services including funeral directors.

A responsibility of the CIS is the control of involuntary admissions to hospital. A police officer can sign a section paper, after consulting with a mental health professional who must confirm the presence of mental illness. If the CIS refuses hospital admission, the CIS is obliged to offer alternative care.

Another unit of the MHC is the Mobile Community Treatment (MCT). It comprises five nurses, four community support specialists (aides), and a social worker, with ten hours weekly medical cover. They provide a seven day service from 8.30 a.m.10.30 p.m., with CIS providing cover at night, for some 180 chronic schizophrenic clients, referred by CIS and hospitals. Many clients are very stable, and attend the MCT office for medications only, with no further interventions being deemed necessary. About 120 clients are offered case management, which usually includes referral.to other agencies for housing and vocational rehabilitation. Most clients are expected to attend the MHC. Much staff time is taken up organising medication and money for the daily pick-ups, based on the same principle as that discussed under the PACT programme, but without the warmth and vitality seen in the PACT staff-client interactions. Much of MCT's services are delivered over a hatchway at the MHC MCT offices, and only about $25 \%$ of staff time is spent on community 
outreach. This may be the result in part of a heavy client load, and in part of MCT clients being considered "too severe" to attempt rehabilitation.

An exciting recent development at MCT has been the development of two Crisis Homes. These are family homes, whose members are willing to foster relatively disturbed individuals for up to two weeks. They are paid a flat rate of $\$ 900$ per month (much less than the cost of in-patient care) although it is proposed that payment may change to a rate per clientday. An advertisement was placed in the local press asking for applications from individuals or families willing to provide a "short-term living arrangement for clients in emotional distress". Twenty-five applications were received. Most were naive or interested only in gaining extra income.

The two families chosen were offered some practical training and ongoing support by the nurse coordinator. Problems experienced are the absence of the families for part of the day, during which other cover is necessary, and protests by neighbours. This was resolved in a meeting with local residents and the foster family. Violence has not been an issue, due in great part to the careful screening of all placements. The response of families and clients has been generally favourable. Clients respond to a well-structured, normal environment, and are usually able to return to their own homes within a few days.

A third facility offered by MHC is Med-Plus. This is a clinic solely for the dispensing and adjustment of medication, and is not dissimilar from an out-patient clinic in the UK.

Support Network, the final unit of the adult services which we visited, is a day centre, the working philosophy of which is democratic care with the service being run by the members who attend the day centre. Support network is eclectic, with $50 \%$ of its members receiving medical care at the day centre itself, the others receiving medical care elsewhere. The professional staff consists of three nurses, and a psychiatrist four hours a week. Each of the nurses takes responsibility for the medical care of 35 members. They are supervised by the psychiatrist and are allowed to adjust drug doses, though not type. The individual members are seen for evaluation by the psychiatrist every six months.

Support Network takes its referrals from hospitals and the CIS. All members have a history of psychiatric illness, but are perceived to have some rehabilitative capability. In general the members of Support Network appear to function at a better level than those of MCT. Support Network has 200 clients. On any given day about 60 members attend the unit. The day centre employs a case management model, and there is a staff-member ratio of between $1: 10 / 25$. The Support Network centre is open $\mathbf{3 6 5}$ days a year. Emphasis is on individual and vocational activities, in an attempt to add structure to the lives of the members. Groups are used, but are not a priority.

The centre, or clubhouse as it is called, is subdivided into three units. The communications unit, which publishes a daily newsletter, has video, computing, photocopying and printing facilities. The cafeteria unit produces low-cost meals, coffee and other drinks for the members. The works unit provides members with work both inside and more rarely outside, the clubhouse. This unit has three transient employment posts (TEP); these are jobs in the competitive market, which the centre guarantees the employer will always be filled, regardless of circumstances, and will be carried out in a satisfactory manner. Employers tend to be agreeable as they know that the job will always be completed. Wages are paid according to the work done by each member. TEP demands a high level of staff involvement.

A fourth unit, the health service unit, is being planned. This will involve members in treating themselves and other members. Members will educate other members and their families concerning their illness, symptoms, and treatment. They will also assist in their physical care. Members will monitor the telephone, and help in the pharmacy/ dispensary. It will be interesting to follow up this novel approach.

Support Network was appreciated by its members. They were keen to show us around their clubhouse and tell us of their achievements. There was a strong sense of belonging, with members being mutually supportive and at ease in their dealings with staff. A good feature was members' involvement in outreach. When a member did not attend the clubhouse because of illness they were visited at home by staff and members. These visits were popular with members.

Hospitals in the Dane County Mental Health Service provided 100 acute psychiatric beds for a population of 300,000 , which is not dissimilar from the UK rate. Some separate long-term in-patient facilities are available. The average in-patient stay is about two weeks.

The mental health service in Madison offers a comprehensive service at all levels, a crisis intervention service, in-patient facilities, a day centre, and long-term community support. The main drawback in the overall service was the poor liaison between units, with little flexibility in client care. The main emphasis should, paradoxically, be on increased community care delivery, in that a community centre should offer support in the community itself, rather than function from the centre as an alternative hospital.

If each of the units in the community services could carry out a well defined function, with good collaboration and cover between the units, and with more fluid movement of clients between each of the 
units, the Madison model of care for the community, in the community, would be very difficult to surpass.

\section{References}

Stein, L. J. \& TEST, K. A. (1980) An alternative to mental hospital treatment. A conceptual model, treatment program, and clinical evaluation". Archives of General Psychiatry, 37, 392-397.

— \& - (1985). The Training in Community Living Model: A Decade of Experience. New Directions for Mental Health Services (No. 26), San Francisco: JosseyBass.

\title{
Compulsory admission to mental hospital in Thailand and England
}

\section{A visitor's view}

\author{
P. KuPITUKSA, Head of Research Unit, Psychology Department, Somdet Chaopraya \\ Hospital, Bangkok, Thailand and Honorary Research Fellow, Department of \\ Sociology, University of Lancaster; J. F. MACMILLAN, Senior Lecturer, University of \\ Birmingham and Honorary Consultant to Academic Unit, All Saints Hospital, Lodge \\ Road, Birmingham B18 5SO; and K. L. SoOTHILL, Senior Lecturer, Department of \\ Sociology, University of Lancaster, Lancaster
}

There are national differences relating to compulsory admission to mental hospitals. As a visitor from Thailand, it was of interest to me (PK) to compare procedures relating to admission, treatment and aftercare of the mentally ill in England and Thailand. In Thailand there is no equivalent of the Mental Health Act 1983. Although there are some legal provisions affecting patients' rights in Thai law, there are no legal provisions concerning 'detained' patients in mental hospitals.

Despite the fact that there is no legal provision for compulsory admission, there are patients who would be considered to have 'escaped' were they to leave hospital, and who may be compared with those admitted or detained under sections of the Mental Health Act 1983. However, without formal legal provision, the role and responsibilities of relatives are more extensive than in England. The relatives are required to take major responsibility for any mentally ill person. There are particular difficulties relating to the absence of catchment areas, as it is not uncommon for patients to be admitted to Somdet Chaopraya Hospital in Bangkok from distant rural areas, which places even more responsibility upon families.

\section{Admission procedures}

A 21 year-old single girl, in her last year at university in Bangkok, serves as a typical example of admission to Somdet Chaopraya Hospital. She lived with a brother and sister, who noted their relative to be sleeping and eating poorly and neglecting herself over a few weeks. She began to say she feared her sister had poisoned her food. The brother was also a student, and the sister in employment some distance from home. When the girl threatened her brother and sister with a knife they decided to seek help, and brought her to the hospital, tied up firmly with a strip of cloth.

Although many patients are admitted bound in this way in Nigeria, this is rare in Thailand. As there is no provision for a doctor, or indeed anyone else to call at home, the position in such a case is that the relatives must bring the patient to hospital. The doctor on duty that day retains medical responsibility for that patient thereafter, and the decision to admit rests with the doctor and the relatives. If both are in agreement then the patient will be admitted, regardless of the patient's view. The relatives are also required to take responsibility for payment for the 